\title{
Improving Winter Traction and Fuel Economy of Car Tires Using Naphthenic Tire Oils
}

\author{
Mika Lahtinen ${ }^{1}$, Kamyar Alavi ${ }^{2}$, Patrik Salomonsson ${ }^{2}$, Markus Hoffmann ${ }^{2}$ and Herbert Fruhmann ${ }^{2}$ \\ 1. NYNASOY, Ayritie 12B, 01510 Vantaa, Finland; \\ 2. NYNAS AB, P.O. Box 10700, 12179 Stockholm, Sweden
}

\begin{abstract}
Naphthenic tire oils were used in winter tire tread compounding. Properties of compounds were compared with similar compounds made of other safe tire oils. Retreaded passenger car winter tires were prepared using the compounds. Traction and rolling resistance of the tires were determined in different weather conditions.It was shown that naphthenic oils may lead to improvement of winter traction and rolling resistance without compromising other tire properties.
\end{abstract}

Key words: Naphthenic oil, winter tire, snow traction, ice traction, dynamic properties, rolling resistance, fuel economy.

\section{Introduction}

Use of naphthenic oils has increased in tire industry. In the Americas, naphthenic oils have been the dominant rubber process oil group since decades. Introduction of European tire oil legislation in 2010 led to their expansion to other areas. Today they are the only group of oils with significant presence at every continent and region: from South America to the US and Europe, from Southeast Asia to Korea and China.

In winter tires, the polymers of tread compounds are of relatively low polarity, and requirement of low temperature flexibility is high. Naphthenic oils are, in particular, favored due to a number of reasons in tread commpounds. Their solvency matches well the requirements of these low polarity and low glass transition temperature $(T g)$, polymers such as $\mathrm{BR}$ (polybutadiene rubber), SBR (styrene-butadiene rubber) with low styrene content and NR (natural rubber). Furthermore, solvent power remains excellent at temperatures below $0{ }^{\circ} \mathrm{C}$. Rubber material extended with a naphthenic oil remains thus flexible and rubbery even if it is used at temperatures approaching such extremes as $-40 \sim-50{ }^{\circ} \mathrm{C}$. Oils need also less heating

Corresponding author: Mika Lahtinen, global technical manager; research fields: tire and rubber oils, tire traction improvement. E-mail: mika.lahtinen@nynas.com. when stored and transferred in cold weather conditions since their wax content is low. And fourth, their content of harmful and carcinogenic polycyclic aromatic structures is also low. They meet both local and global requirements for environmental safety and workplace hygiene.

Performance improvement of tires has led in recent years to huge steps being taken in development of polymers, fillers and their coupling to each other. One of the best tools to improve winter tire performance, however, the tire oil, has sometimes been overlooked. An oil which retains its plasticizing efficiency at low temperatures may yield improved traction on snowy and icy roads without compromising, e.g., the wear resistance, or traction at higher temperatures.

In this paper, we show that low temperature stiffness of tire tread compounds and winter traction of tires can be significantly affected by selecting the tire oil appropriately. It leads to better safety in traffic.

\section{Predicting Winter Tire Performance}

Tire R\&D requires experience, money, and in particular, time. Furthermore, often a lot of luck is also needed in tire testing: testing conditions may affect significantly the results and delay the testing schedules. Tire performance is hence often predicted by carrying 
out laboratory scale compounding studies. Tire properties such as traction, mileage and durability, behavior at extreme handling conditions, or RR (rolling resistance), are predicted by determining how rubber compounds behave in laboratory tests when exposed to static and dynamic stresses [1].

Winter tire development is also relying heavily on information obtained in DMA (dynamic mechanical analysis) of tire tread compounds [2]. This is partly justified as winter traction is mostly governed by tread rubber properties. Yet correlation between DMA results and tire tests is not necessarily good.

In a typical DMA of tire tread compounds, glass transition temperature $(T g)$ of oil affects the rubber behavior. Higher oil $\mathrm{Tg}$ leads to higher compound $\mathrm{Tg}$, which is often accompanied with a higher energy loss (tan delta) at $0{ }^{\circ} \mathrm{C}$. It in turn is the most common laboratory-based wet traction indicator: the higher the tan delta at $0{ }^{\circ} \mathrm{C}$, the better the traction. Aromatic tire oil (distilled aromatic extract, DAE) and RAE (residual aromatic extract) with higher $T g$ 's yield typically higher compound $\mathrm{Tg}$ 's and 5-15\% higher tan deltas at $0{ }^{\circ} \mathrm{C}$ than other tire oils such as TDAE (treated distilled aromatic extract) and naphthenic oils with lower aromatic contents. Correlation between tan delta and traction, however, is not perfect and relatively large differences in tan delta can be found with no differences in traction tests.

Winter traction of tread rubber can be estimated by looking at a few commonly accepted parameters which one again obtains using DMA. The most common is tan delta at $-25^{\circ} \mathrm{C}$; yet the correlation of it with tire test results is not very good. A lot better correlation can be found between dynamic stiffness (shear modulus $G^{*}$ or tensile modulus $E^{*}$ ) and traction on snow and ice. The lower the tread rubber stiffness at extremely cold, the better the traction.

\section{NYNAS Tire Testing Program}

Numerous rubber compounding studies carried out by NYNAS have consistently indicated that heat build-up and energy loss of rubber compounds under dynamic loading can be reduced by using naphthenic oils. Effects of different oils on low temperature flexibility, however, have not been studied extensively. Tire manufacturers naturally carry out such tests, but results and correlations are typically not shared. It, however, has been shown that naphthenic oil extended SSBR/BR compounds exhibit a lower dynamic stiffness than the same compound extended with TDAE [3]. It is expected to result in improved traction in winter. If winter tire performance, however, is concluded from other commonly used indicators such as tan delta, there is often a controversy: oils with higher aromatic content yield compounds with higher tan delta at the whole temperature range. Yet higher $T g$ is expected to lead to poorer low temperature properties.

To verify the correlation between laboratory compounding studies and real tire performance, we kicked off an extensive tire testing program. Winter tire tread compounds were prepared using state-of-the-art raw materials such as functionalized solution SBR and highly dispersible, high surface area silica. Four different tire oils were used as variables in the program: naphthenic oils NYTEX ${ }^{\circledR} 840$ and NYTEX ${ }^{\circledR} 4700$ and so called Group I manufacturing process side stream oils TDAE and RAE. All these are known to be used in winter tires, and they all meet the European tire oil legislation's requirements for the content of polycyclic aromatic hydrocarbons.

Why to carry out such an extensive (and costly) study? As said, tire performance can only partly be predicted using the rubber compound property measurements. Tires are complex, and tread rubber compound is only one of the factors influencing tire behavior. So NYNAS wanted to verify that predictions are met and tire performance can be affected by selecting the tire oil in the right manner. Furthermore, tire testing in cold conditions is difficult and expensive, so the work might support tire companies without specific testing facilities. 


\subsection{Description of Tire Testing Program}

The program was composed of four parts. First, tire tread compounds were prepared in an intermeshing laboratory-scale mixer, and the only change in four compounds was the oil type. In other words, all other raw materials and mixing programs at each of the three mixing stages were identical, and also oil content in each compound was the same. Target values for Shore A hardness, modulus at $300 \%$ extension and dynamic stiffness (dynamic complex modulus $\mathrm{E}^{*}$ ) were determined. In particular, traction in winter conditions is strongly affected by the compound hardness, and thus equal hardness was targeted. In addition, a typical drawback of excellent winter traction is lack of sufficient stiffness and slow steering response on dry and warm roads and at high driving speed. Therefore, a target was set for moduli in both static and dynamic conditions. The recipes in the first part are shown in Table 1.

In the second part, another set of lab compounds was prepared, yet now with small modifications in the recipes. Each recipe was slightly finetuned to meet the target values. In tire industry, a simple 1:1 drop-in is often favored, but finetuning may maximize the potential of each oil.

In the third part, compounds were prepared in an industrial 250 liter Banbury mixer at Kraiburg Austria. These were then used in retreading: carefully selected tire carcasses were retreaded at Reifen Hinghaus $\mathrm{GmbH}$ in Germany and cured according to their standard tire curing procedure. And finally, tire traction was extensively tested in cold wet, snowy and icy conditions, and RR on a large drum in laboratory conditions.

Recipes used in the industrial compounding, as well as selected properties of compounds are presented in Table 2. It can be seen that scale-up from laboratory mixer to a production-scale mixer was successful, and target values for Shore A hardness and moduli were obtained. In addition, differences in compound viscosities and curing rates were small, so processing of compounds to tire treads took later place without any problems. Tires were built in different sizes to get more experience from how they perform in real road conditions mounted to different-sized vehicles.

\subsection{Description of Tire Tests}

Wet traction and RR tests were carried out by Prüflabor Nord GmbH in Germany. UNECE (United Nations Economic Commission for Europe) Regulation No. 117, which specifies how the tire approval testing is done in the European Union, was followed in testing. Furthermore, the regulation is used in determining the European tire label ratings which a consumer buying the tires can see before making the decision. Effectively, the same regulation is used to determine tire label ratings in other countries such as Japan, South Korea and Brazil. And more importantly, when China implement her new tire regulation and labelling scheme, test conditions and methods are again the same as in ECE R.117.

In the wet traction test, the SRTT (standard reference test tire) method was used, i.e., breaking forces of tested tires were compared with a 16" uniroyal reference tire. Results were then indexed, and tire label ratings are based on the indexes.

Table 1 Rubber compound recipes in the first part of NYNAS Tire Testing Program (laboratory scale compounding). Recipes are property of Kraiburg GmbH and cannot be fully disclosed.

\begin{tabular}{lllll}
\hline Raw materials & Compound 1 (NYTEX $\left.{ }^{\circledR} 4700\right)$ & Compound 2 (TDAE) & Compound 3 (RAE) & Compound 4 (NYTEX $\left.{ }^{\circledR} 840\right)$ \\
\hline fx-SSBR & 50 & 50 & 50 & 50 \\
Nd-BR & 25 & 25 & 25 & 25 \\
SMR 20 & 25 & 25 & 25 & 25 \\
Silica HD, $160 \mathrm{~m}^{2} / \mathrm{g}$ & 83 & 83 & 83 & 83 \\
Oil & 42 & 42 & 42 & 42 \\
\hline
\end{tabular}


Table 2 Recipes in the third part of NYNAS Tire Testing Program. Selected properties of rubber compounds.

\begin{tabular}{|c|c|c|c|c|}
\hline Raw materials & Compound 1 (NYTEX $\left.{ }^{\circledR} 4700\right)$ & Compound 2 (TDAE) & Compound 3 (RAE) & Compound 4 (NYTEX $\left.{ }^{\circledR} 840\right)$ \\
\hline fx-SSBR & 45 & 45 & 45 & 45 \\
\hline Nd-BR & 35 & 35 & 35 & 35 \\
\hline SMR 20 & 20 & 20 & 20 & 20 \\
\hline Silica HD, $160 \mathrm{~m}^{2} / \mathrm{g}$ & 81 & 83 & 81 & 83 \\
\hline Oil & 44 & 44 & 45 & 43 \\
\hline $\begin{array}{l}\text { Shore A hardness } \\
\text { (target } 65 \pm 2 \text { ) }\end{array}$ & 66 & 66 & 67 & 67 \\
\hline $\begin{array}{l}\text { Modulus at } 300 \%(\mathrm{MPa}) \\
\text { (target } 12.0 \pm 1.0)\end{array}$ & 11.2 & 12.0 & 12.3 & 12.7 \\
\hline $\begin{array}{l}\mathrm{G}^{*} \text { at } 60^{\circ} \mathrm{C}(\mathrm{MPa}) \\
\text { (target } 15.5 \pm 1.5)\end{array}$ & 15.2 & 15.4 & 15.7 & 16.7 \\
\hline
\end{tabular}

Table 3 Wet traction and RR test results.

\begin{tabular}{lllll}
\hline Tire property & Tire 1 & $\begin{array}{l}\text { Tire 2 } \\
(\text { NYTEX }\end{array}$ & $\begin{array}{l}\text { Tire 3 } \\
(\text { RAE })\end{array}$ & $\begin{array}{l}\text { Tire 4 } \\
\left(\text { NYTEX }^{\circledR} 840\right)\end{array}$ \\
\hline Wet braking index & 1.41 & 1.42 & 1.39 & 1.40 \\
Wet braking rating $^{\mathrm{a}}$ & $\mathrm{B}$ & $\mathrm{B}$ & $\mathrm{C}$ & $\mathrm{C}$ \\
RR & 8.34 & 8.78 & 8.53 & 8.57 \\
RR rating & $\mathrm{C}$ & $\mathrm{C}$ & $\mathrm{C}$ & $\mathrm{C}$ \\
\hline
\end{tabular}

Note: ${ }^{\mathrm{a}}$ : wet braking ratings: $1.25<\mathrm{C}<1.40,1.41<\mathrm{B}<1.55, \mathrm{~A}>1.55$

${ }^{\mathrm{b}}$ : rolling resistance ratings: $10.5>\mathrm{E} \geq 9.0,9.0>\mathrm{C} \geq 7.8,7.8>\mathrm{B} \geq 6.5$.

Winter performance of tires was tested on snow and ice by Test World Oy. The same tires were shipped to Northern Finland and tested for braking distance on ice and snow. Testing temperature was ca. $-7{ }^{\circ} \mathrm{C}$, and braking distance from $30 \mathrm{~km} / \mathrm{h}$ to $5 \mathrm{~km} / \mathrm{h}$ on snow and $20 \mathrm{~km} / \mathrm{h}$ to $5 \mathrm{~km} / \mathrm{h}$ on ice was measured. The test procedure is developed by Test World; there is not yet any commonly accepted method to test winter traction and thus no winter performance labelling either. The work in Europe, however, is underway to display at least qualitative information to consumers about winter tire performance in the future.

\section{Results and Discussion}

\subsection{Wet Traction and RR Test Results}

Wet traction results are presented in Table 3. It was found that four tested tire specifications yielded very similar indexes, namely from 1.39 to 1.42 . Considering the deviation in the test, it can be noted that wet traction of each tire specification was equal. Yet there was a $10 \%$ difference in tan delta at $0{ }^{\circ} \mathrm{C}$ : RAE which even had a marginally lower wet traction index exhibited the highest tan delta at $0^{\circ} \mathrm{C}$.
RR of a tire accounts for $15-30 \%$ of energy losses of a vehicle. Therefore, reducing the RR can lead to an immediate improvement of vehicle's fuel economy and lower carbon dioxide emissions. Typically, $50 \%$ of passenger car tire's $R R$ is caused by the tread compound [4], so decrease of energy loss of tread compound results almost certainly in better fuel efficiency. In rubber compounding laboratory, the property correlating the best with $\mathrm{RR}$ is the tan delta at $50 \sim 70{ }^{\circ} \mathrm{C}$ (corresponding to frequencies which are typical at the driving speed of ca. $80 \mathrm{~km} / \mathrm{h}$ ). Again, behavior is typically affected by oil $T g$ : DAE or RAE with high aromatic content and thus higher $T g$ yields also higher tan delta at $50 \sim 70{ }^{\circ} \mathrm{C}$.

Numerous studies carried out by NYNAS, however, indicate that there are also other factors affecting the rubber behavior: naphthenic oils are known for their tendency to decrease tan delta in that frequency and temperature range. Many tire polymers have relatively low polarity, so only a limited number of aromatic groups in oil is desired to ensure compatibility. In particular, this is the case in all season and winter tires which are often composed of NR, BR and low $T g$ SBR, 
which all have only a very few polar groups or moieties. Their compatibility with naphthenic oils is extremely good.

Again, RR was determined using the ECE R.117 method. Results are presented in Table 3. For tire labels, results are converted to different ratings. It was found that all tested tire specifications yielded the same European rating, namely $\mathrm{C}$ (in the Japanese tire label, it would be A). Between different specifications, however, there was a difference. The best oil in the test, i.e., NYTEX $^{\circledR} 4700$, yielded $5 \%$ lower RR than TDAE. Consistent with the earlier mentioned numerous lab studies, naphthenic black oil improved fuel economy. And more importantly, it took place without affecting the traction.

One can naturally discuss whether the 5\% improvement is significant. In most cases, it is even not sufficient to improve tire label rating by one class: an average improvement needed to move from one class to another is $14 \%$. Yet naphthenic oils offer an excellent additional tool to improve tire performance without undesired compromises in other properties. An experienced rubber compounder surely acknowledges that, to reach the best tire label ratings, he or she needs to look at several compounds and several raw materials, in addition to tire cord, tire design and tire construction development. Tire oil, and tread compound oil in particular should definitely be one of those to look at.

\subsection{Tire Testing in Winter Conditions}

An essential feature of all season and winter tires is their traction in cold winter weather. Driver needs to control the vehicle even if there is a sudden change in weather conditions and only moderate or poor traction on the road. Winter traction is mostly governed by tread rubber compounding. Requirements differ remarkably from summer tires: compound needs to remain soft and flexible at extremely cold temperatures. It, however, should exhibit sufficient stiffness when winter is over and road surface still cold but dry.

Many of naphthenic tire oils have a really low $T g$, ranging from $-52{ }^{\circ} \mathrm{C}$ of $\mathrm{NYTEX}^{\circledR} 230$ to $-76{ }^{\circ} \mathrm{C}$ of NYTEX $^{\circledR}$ 810. Low $T g$ ensures that rubber does not turn glassy even if temperature reaches record low values. The same can be seen in dynamic modulus: stiffness of rubber compounds extended with naphthenic oils remains low at cold. Many of the world's leading winter tires are extended with naphthenic oils to improve traction in cold weather.

Results of snow and ice braking tests are shown in Table 4. Braking performance is indexed using NYTEX $^{\circledR} 4700$ as a reference tire. Dynamic stiffnesses of tread compounds are also presented in the same table. As expected, high dynamic stiffness of RAE compound led to longer braking distances on both ice and snow (even if oil loading was the highest in RAE tyre). The three other oils exhibited the same traction on snow. Weather corrected braking distance of the three other oils was within centimeters.

On ice, however, there were differences: naphthenic oils and especially NYTEX ${ }^{\circledR} 840$ performed better. RAE was $6 \%$ worse than NYTEX ${ }^{\circledR} 840$. Again, one can argue how much is meaningful in a braking test. Fortunately, a driver may never have to "utilize" the

Table 4 Results from snow and ice breaking tests.

\begin{tabular}{lllll}
\hline Tire property & $\left.\begin{array}{l}\text { Tire } 1 \\
(\text { NYTEX }\end{array}{ }^{\circledR} 4700\right)$ & $\begin{array}{l}\text { Tire } 2 \\
(\text { TDAE) }\end{array}$ & $\begin{array}{l}\text { Tire 3 } \\
(\text { RAE })\end{array}$ & $\begin{array}{l}\text { Tire } 4 \\
\left(\text { NYTEX }^{\circledR} 840\right)\end{array}$ \\
\hline Snow braking distance $(\mathrm{m})$ & 9.10 & 9.09 & 9.45 & 9.08 \\
Ice braking distance $(\mathrm{m})$ & 10.88 & 11.07 & 11.42 & 10.72 \\
Snow braking index & 100.0 & 100.1 & 96.3 & 100.2 \\
Ice braking index & 100.0 & 98.2 & 95.3 & 101.4 \\
Dynamic tensile modulus at $-25^{\circ} \mathrm{C}(\mathrm{MPa})$ & 84.7 & 97.1 & 126.6 & 86.4 \\
Tan delta at $-25^{\circ} \mathrm{C}$ & 0.282 & 0.290 & 0.370 & 0.263 \\
\hline
\end{tabular}


Table 5 Estimated mileages until $3 \mathrm{~mm}$ tread depth.

\begin{tabular}{lllll}
\hline Tire property & $\begin{array}{l}\text { Tire 1 } \\
\left.\text { NYTEX }^{\circledR} 4700\right)\end{array}$ & $\begin{array}{l}\text { Tire 2 } \\
\text { (TDAE) }\end{array}$ & $\begin{array}{l}\text { Tire 3 } \\
\text { (RAE) }\end{array}$ & $\begin{array}{l}\text { Tire 4 } \\
\left.\text { (NYTEX }^{\circledR} 840\right)\end{array}$ \\
\hline $\begin{array}{l}\text { Average mileage estimation when } \\
\text { extrapolated to 3 mm tread depth }(\mathrm{km})\end{array}$ & 40,300 & 41,900 & 40,400 & 39,000 \\
\hline
\end{tabular}

improvement; e.g., difference of $70 \mathrm{~cm}$ between NYTEX $^{\circledR} 840$ and RAE tires in the test condition of 20 $\mathrm{km} / \mathrm{h}$. If the speed, however, was $50 \sim 60 \mathrm{~km} / \mathrm{h}$, difference would be several meters and better performance might save lives. An experienced winter tire compounder would definitely welcome the improvement.

Values of tan delta at $-25{ }^{\circ} \mathrm{C}$ are also shown in Table 5. It can be concluded that correlation of tan delta with winter traction is poor.

Winter tire market is growing, and especially in China winter tire use is increasing. Traditionally, the winter tire market has been dominated by a handful of manufacturers only, but recently several newcomers have extended their focus to these markets. Naphthenic oils can improve performance in cold winter conditions and hence improve driving safety.

In many markets such as the US and South Korea, so called all season or four season tires are common. Consumers have just one set of tires, and there is no need to change them in the autumn and again in the spring. The tires, however should perform well in all temperatures and weather conditions. With naphthenic oil, traction at the most difficult conditions may be boosted. Hence, naphthenic oils provide an excellent tire compounding tool to manufacturers of all season tires, too.

\subsection{Testing of Wear Resistance}

Wear resistance improvement of tires may become more important in the future. Extensive work to improve fuel efficiency and reduce tire weight may have taken place by reducing tread depth and filler content and using a lower tire component thickness. It could compromise resistance to wear and overall durability. The four tire specifications were also tested for mileage: they were mounted on several taxis in
Austria and Southern Germany, and treadwear was followed during the winter season 2016-2017. Naturally, taxi testing is not accurate and differences between different cars having the same tread rubber composition can be large. Yet testing may reveal if there are significant differences between specifications, or in general serious issues with wear resistance.

Tread depths of different tires were extrapolated to 3 $\mathrm{mm}$ remaining tread depth. Results for each tire specification are presented in Table 5 .

\section{Conclusions}

NYNAS tire test program confirmed that naphthenic oils can improve tire performance. RR or winter traction improvement was achieved without compromising any other part of tire performance. In the best case, tire RR rating improvement might be possible.

Car manufacturers are pushing tire companies more and more to reduce RR to meet their own targets for $\mathrm{CO}_{2}$ emissions. Winter tire markets in turn are growing faster than the industry in general. Naphthenic oil provides tire compounders with an excellent tool to improve performance further.

\section{Acknowledgments}

Dr. Wolfgang Loreth of Kraiburg Austria GmbH is acknowledged for his support during the Tire Testing Program.

\section{References}

[1] NHTSA. 2009. Tire Fuel Efficiency Consumer Information Program Development: Phase 2-Effects of Tire Rolling Resistance Levels on Traction, Treadwear, and Vehicle Fuel Economy. Technical report of NHTSA.

[2] Futamura, S. 1990. "Effect of Material Properties on Tire Performance Characteristics, Part II-Tread Material." Tire Science \& Technology 18: 2-12.

[3] Hoffmann, M., and Rahmn, I. J. 2014. "Naphthenic 
Plasticizers for High-Performance Tires." Rubber World 250 (6): 26-9.
[4] Uhrlandt, S., and Blume, A. 2002. "Development of HD-Silicas for Tires." Rubber World 226: 30-1. 